\title{
Complex synthesis of factors for modern development of welfare of territorial communities
}

\author{
Valentyna Varuk ${ }^{1,1}$, and Olena Parkhomenko \\ ${ }^{1}$ Education and research institute "Karazin business school" V.N. Karazin Kharkiv National \\ University, 1, Myronosytska St., Kharkiv, 61002, Ukraine
}

\begin{abstract}
It is substantiated that providing citizens' welfare, which occurs through a complex synthesis of factors, is one of those that is in the constant field of view of the socio-economic sphere. Analyzing, systematizing and summarizing the scientific works of many scientists, welfare factors are identified that are important for prospects' understanding of territorial communities' functioning, their role and place in the national economy, conditions that ensure competitiveness, and directions for improving efficiency of activities. At the same time, factors of welfare of territorial communities can be individual and subjective, with different significance for different people, may vary throughout a lifetime, and may also have a direct or indirect impact on each member. So, some people pay more attention to financial wealth, others - to their physical and/or mental health. The following factors of welfare of territorial communities are proposed and described: socio-economic, demographic, legal, political, cultural and psychological. It is concluded that to date, in the context of intensive transformations and reforms, communities' welfare is a product of many and often interconnected factors, understanding the impact of which is important for determining competitiveness of the communities and directions to improve efficiency of activities.
\end{abstract}

\section{Introduction}

Determining prospects of functioning of territorial communities, their role, place, conditions of activity is important in the modern economy of the country. There is a need to study welfare factors to ensure the above. Analyzing and systematizing the scientific works of many scientists $[1,2,3]$, it was established that the question of which factors can affect the social life's satisfaction remain relevant forever. Therefore this study is aimed at researching and describing welfare factors, as there is no generalization of this issue.

\section{Summarize factors that affect welfare of territorial communities}

In conditions of intensive transformation and reforms, welfare factors of territorial communities need improvement and development. It is necessary to identify several important groups of welfare factors of territorial communities, namely (Fig. 1):

\footnotetext{
${ }^{1}$ Corresponding author: varuk@karazin.ua
} 


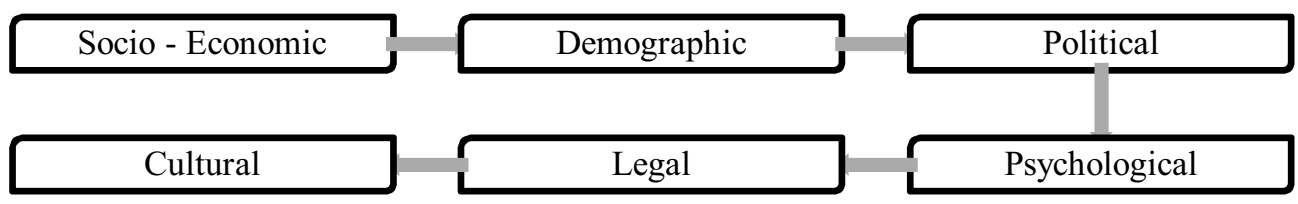

Fig. 1. Factors of growth of welfare of territorial communities (developed by the author)

The first factor is social and economic welfare of members of territorial communities, namely the level of prosperity and life's quality of people. Scientists determine social and economic welfare of territorial communities' members as a process of improving the life's quality of people, which living in relatively isolated and sparsely populated areas. Economic welfare of community members can be measured by various indicators such as GDP and other indicators that reflect population welfare (for example, literacy, doctors' number, pollution levels, etc.). Economic welfare of community members has a positive impact on the lives of the population and society as a whole.

Regarding social welfare of community members, it manifests itself in a sufficient human satisfaction with a dynamic system of social ties, with a presence of positive interpersonal relationships that manifested in the form of friendship, love and support. A level of social welfare of community members can be high when a person has the guarantees of good living conditions, decent education, medical care, etc. A career growth can also have a positive impact on human welfare. A work that brings pleasure allows a person to self-fulfill, provides social guarantees and stable income.

The social and economic factors of community members' welfare characterize a level of creating conditions for the fullest realization of labor and intellectual potential of population, providing them with material wealth, decent living standards, etc [3].

Workforce welfare is largely determined by a situation on the labor market and an employment level. Therefore, an effective regulation of the labor market and employment is one of the main social and economic factors of welfare. A special place among the social and economic indicators of community welfare is investment in human capital, that is, an asset of all qualities and abilities of a person, able to positively influence a development of all spheres of society life. Labor employment is not an absolute and only condition for ensuring material welfare of a person and his family. An important role is played by the wages size. One of the most significant factors that determining the size payments in the modern state is a level of minimum wage, which is related to the basic social guarantees.

The fundamental social and economic factor of disabled population welfare is formation of social funds (the Pension Fund, the Social Insurance Fund and the Compulsory Health Insurance Fund) to provide, assist and support socially vulnerable groups of the population. A main source of formation of such funds is deduction of employers and self-employed citizens. These contributions are calculated as a percentage of the workers' total income. Contribution collection and control over the correctness of their accrual are carried out by tax authorities. Funds are spent on provision of guaranteed health insurance services, pension payment, benefits, compensations to certain social categories [4].

A financial state and unemployment are considered as factors which are part of the overall political and economic environment that affects territorial communities' welfare. Today, there is an impact of a society general state on their welfare, including the growth of aggression in society, false reports and fake news in the media. Money provides access to other factors that affect community members' welfare. Meeting basic needs (such as housing, food, warmth, clothing, etc.) is a goal in itself, but it also gives a chance to have a steady life. At the basic level, employment is related to community members' welfare, because satisfaction from work (desired work satisfaction) is an important factor of welfare.

Educational skills concern not only knowledge acquisition in a formal sense, but also a general desire to expand their knowledge and to be exposed to new ideas. For many, 
educational opportunities are not only related to their own professional development, but also with a financial ability to send their children to the educational institutions they would like to attend [3,5]. Health is seen as a very important factor affecting community members' welfare and is understood as absence of illness, suffering or any weakening or disturbance of public life. First of all, it is physical preparedness and physical exercise that affect an energy level, the cardiac performance and physical form. In a similar way, nutrition affects human health, and therefore welfare.

Innovative factors of community members' welfare include: achievements, a level of scientific and technical development, volumes of research results, degree of introduction of innovations and information technologies, a level of result accessibility of scientific and technological activities, innovations, information technologies, etc. A level of environmental pollution, mechanisms for regulating nature use, ensuring protection, an impact of weather are factors of community members' welfare. These factors, as well as the territory features and an availability of natural resources, may have a positive impact on welfare.

Therefore, the social and economic factors of community members are the following elements: income, employment, housing, education, work, duration and quality of life, leisure, an environment, the happiness levels.

The next factor of welfare of territorial communities is a connection with demographic characteristics. The demographic factors of territorial communities' welfare include a population size, density, a structure by age and sex, a migration level and its geographical distribution, as well as these parameters' dynamics.

Moreover, the predicted link between demographic parameters and territorial communities' welfare is considered from two points of view. According to the first perspective, changes in a nature of population growth create changes in welfare. The second perspective is based on the fact that changes in welfare lead to changes in the population characteristics. Despite the fact that the basic hypothesis about the existence of the relationship between welfare and the population characteristics lies at the heart of the demographic system and comes to ahead, these relationships have not yet been studied.

According to the research results of the International Bank for Reconstruction and Development, the greatest impact on community members' welfare provides a subject belonging to different gender groups: women are less than men satisfied with life spheres, and at an emotional level they experience tension and distrust regarding their health. Subjects' belonging to different ages and educational groups also affects welfare level, but in somewhat lesser degrees (satisfaction with age of life spheres decreases and tensions increase). By a influence's degree on a level of person welfare, an environment of human habitation has no less significant effect (city or village): rural inhabitants, in comparison with town inhabitants, are more satisfied with a social and economic state of the country, their material provision (a material situation, living conditions, leisure, an opportunity to spend holiday), an education and relations with different generations of relatives [6].

That is, we can conclude that, according to a person belonging to one or another social and demographic group, a large difference is demonstrated by a cognitive component of welfare, which includes an assessment of satisfaction or dissatisfaction with life aspects.

Legal factors of territorial communities' welfare are the third factor, which are oriented on a formation and development of regulatory and legislative bases that ensures guarantees' observance of human rights and freedoms in all spheres of its life, as well as an organization of a society life in accordance with a law in force in the state. The legal factors of community members' welfare are based on legal norms which represent an official expression of values and norms of morality that are embodied in legal laws. Laws are a basic foundation for social stability, security and welfare of social life. 
Scientists acknowledged an influence of current governments and politicians on the daily lives of territorial communities' members through decisions and laws, which implemented by politicians and government officials, and also by creating economic and political stability, providing services (including social and medical services), jobs and investments in cultural objects (museums, theaters, cultural centers, etc.) [6, 7]. So, political institutions with a high degree of trust can convert this trust into an influence on community members' welfare, while ensuring respect for human rights and a law rule. Freedom to express their opinions without sanctions from the authorities is seen as a key factor of welfare. A feeling of general confidence that human rights are respected and that they are protected by the authorities gives a certain understanding and, thus, positively influences on territorial communities' welfare.

A main mechanism that motivates a person to recognize and follow to legal norms is formal social control, the organization and implementation of which is an indispensable condition for an existence of society and the state as a whole. It includes two interconnected subsystems [8]:

- Subsystem tracking is a timely detection and elimination of undesirable behavior, maintenance and promotion of the desired;

- Subsystem of influence is to encourage people to comply with the procedure established by law.

That is, the legal factors, in aggregate, namely norms, laws, freedom, contribute to the creation and maintenance of stable, safe, comfortable conditions of social life, which are the foundation of community welfare.

The fourth factor of community members' welfare is a political one, which are associated with the main mechanisms for a formation and implementation of state policy, which are an integral part of the state's domestic policy and are focused on solving current problems. Its tasks are to harmonize social relations, create conditions for a progressive development of a social sphere, improve conditions, methods and quality of life, provide necessary assistance to the population, support and protect socially vulnerable groups and groups of territorial communities' members.

National projects, social programs and state standards promote to increase territorial communities' welfare. These policy tools most fully reflect the priorities, directions, goals and objectives of social policy, identify social problems and groups of people who need special attention, as well as specify methods for solving existing social contradictions. Social programs are created and operated in order to consolidate valuable, highly skilled professionals, increase their level of material satisfaction, and facilitate a creation of additional motivation for career growth in labor activity. State standards, which are established by the state norms and regulations with an aim $[2,4]$ :

- To determine a guaranteed structure and norms of consumption of material goods and services by citizens;

- Carrying out a single social policy in different regions of the country;

- Assessing the living standards of the population and the implementation of social policy, etc.

That is, these instruments determine a lower line of welfare and are set in a form of natural, cost, time and financial norms and standards, rules and regulations, which governing a procedure for their establishment and application.

Cultural activity is the fifth factor, which contributing to welfare of individuals, families and communities on time. Examples of recreational indicators for territorial communities' members can be the following: visits to theaters, concerts, museums, that is, possession of freedom and resources for participation in cultural programs. Formation of cultural factors for territorial communities' welfare provides for the development of personality. Leisure contributes to goals 'number that improve community members' 
welfare: providing relaxation, entertainment, escape from reality and from everyday work and realization, the opportunity to be creative and practice your hobbies.

Cultural factors of community members' welfare (moral values and norms, spirituality, religion, social ideals) are associated with a formation and development of social culture, which is understood as a culture of social life, communication, social relations and interactions that provide a social system's «grip», a social life's stability and a progressive development of social actors at different levels [9].

Thus, moral values and norms form a basis of moral culture and play an important role in regulating social relations and interactions, regulation or ensuring social life and prosperity, stability and order in society. A development of an individual spiritual world through an art's attraction is a mechanism for a social culture's formation. And also religion, as spirituality and religion contribute to welfare sense of every person. But despite this statement, these two concepts are not considered the same. The population speaks of itself more about spiritual rather than religious. Social ideals are interpreted as higher social goals and models, and also form a foundation of social culture. They are formed on a basis of universally recognized values, and also structure and organize a world picture. In a way, they organize an activity of social subjects and communities in general, and define their strategic target points.

That is, together cultural factors will promote an individual socialization in the community through a formation of social qualities, knowledge, etc.

The sixth psychological (subjective) factor can be attributed to a person's mood that positively or negatively affects their welfare. In turn, welfare sense can affect a person's mood. It largely depends on a person's nature and a general views on life. Subjective welfare of a person also affects a number of uncontrolled factors, such as luck, fate, genetics and personality, in which people can have very little influence. Satisfaction, which follows from a feeling of a good attitude towards yourself or belief in yourself, as well as values, self-realization, recognition, success, can be a great positive factor in person's welfare. A personal growth and development have a positive impact on welfare, which contributes to both stability and predictability in life and work.

The psychological factor of welfare affects a people understanding of a nature and purpose, the awareness and experience of a life meaning, and is one of the most important factors of human welfare. Not perceiving itself as the universe's part without thinking about its purpose, without feeling responsible for welfare of other people - a person can't be safely herself. So, Carole D. Riff, author of well-known welfare concepts, based on an integration of various theories, proposed a generalized model of psychological welfare [10].

Psychological welfare is achieved through two instrumental goals: stimulation (activation) and comfort. Stimulation refers to activity that causes excitement, including mental and sensory stimulation and physical effort. Comfort is a somatic and psychological state, based on a lack of thirst, hunger, pain, fatigue, fear, extreme unpredictability, etc. Activating within a pleasant range and comfort is a positive connection to physical welfare.

Psychological welfare is a complex and multifaceted construct that is directly related to its own personal experience and consistent living activity, which each considers to be adequate to its needs and desire. This type consists of [11]:

- Life satisfaction: what everyone thinks about their lives;

- Particular satisfaction: a determining factor is a subject's life such as work, health, family, friendship and economics;

- Positive symptoms: an experience of pleasant positive emotions;

- Negative symptoms: feeling of negative emotions.

In this case, according to Abraham Maslow, centers of psychological welfare are in a realization and development of a genuine individual potential [1]. Psychological welfare is achieved when a person lives by agreement with oneself and reaches the delivered. That is, 
when life's activities are consistent with personal values. In this case, the components of psychological welfare are: autonomy, personal growth, positive relationships, happiness (which can be explained by $50 \%$ genetic factors), competition and life purpose.

\section{Conclusions}

Community members' welfare depends on the formation of the necessary conditions for the socio-economic growth of the territory. Understanding of welfare factors is an important for the determination of the communities' competitiveness and the areas of improving the activities' efficiency.

Thus, the socio-economic factors of communities' welfare are related to optimization of a labor market and employment, ensuring incomes' decent level, protecting the purchasing power of wages, investing in human capital and creating funds for the provision of socially vulnerable groups. The demographic factors, namely: population size, density, structure by age and gender, migration level and geographical distribution, have a significant impact on welfare of everyone. Legal factors of community members' welfare are represented by social legislation, which ensures observance and protection of human rights and freedoms, the spread of legal awareness, legal culture and formal social control.

National projects, social programs and state standards are instruments of political factors that help harmonize social relations, create conditions for social development, improve conditions, way and quality of life, provide necessary assistance to the population, etc. The main cultural factor of welfare of man and the community as a whole is a full socialization, no matter what the role of others was. That is, it is a process of mastering the socio-cultural experience of previous generations, the formation of social qualities and properties, knowledge and skills, values, ideals and norms of social behavior, through which the individual becomes a full member of society. Psychological factors of welfare are connected with self-confidence, adequate self-evaluate, positive attitude to life, goodwill, sociability, emotional stability, etc.

So, territorial communities' welfare is carried out through a comprehensive synthesis of factors that influence on our lives' satisfaction.

\section{References}

1. Yu.I. Kashliuk, The main factors influencing the individual's psychological welfare, Problems of modern psychology, 34, 170 - 186 (2016)

2. O.V. Maistrenko, O.V. Mazorenko, Social programs: concept and structure, Sustainable development of the economy, 28, 44 - 49 (2015)

3. A.S. Mahdich, The social factors' influence on economic growth: The national aspect, Nobel Economic Journal, 1 (8), 68 - 78 (2015)

4. N.O. Stefanopulos, Redistrations and Territorial Communities, University of Pennsylvania, 160, 1379 - 1477 (2012)

5. The European Commission, Well-being, Eurobarometer Qualitative Studies, 1, 24 $50(2011)$

6. International Bank for Reconstruction and development, Gender issues' evaluation in Ukraine, Public Disclosure Authorized, 1, 28 - 74 (2016)

7. O.O. Karmazina, Social indicators of Ukraine population's living standards, State service of Ukraine statistics, 1, 15 - 167 (2018)

8. V.M. Palchenkova, Review of foreign concepts of social control, Theory and history of state and law, 1 (18), 3 - 7 (2015) 
9. A.V. Furman, O. Morshchakova, Social culture, Psychology and Society, 1, 26 - 36 (2015)

10. K.D. Riff, C.L. Keies, The rebuilt structure of psychological welfare, Journal of personality and social psychology, 69 (4), 719 - 727 (1995)

11. H. Shamborovskyi, Welfare as a socio-psychological category in economic science, Economy, 2 (122), 78 - 82 (2013) 